\title{
Concepção do professor do ensino comum em relação à aprendizagem, currículo, ensino e avaliação do aluno com deficiência intelectual
}

Teacher's conception of regular teaching about to learning, curriculum, teaching and evaluation of the student with intellectual disability

Concepción del profesor de educación ordinaria en relación al aprendizaje, currículum, enseñanza y evaluación del alumno con discapacidad intelectual

\author{
Vera Lucia Mendonça Nunes \\ Mestra pela Universidade Estadual Júlio de Mesquita Filho, Marília, São Paulo, Brasil. \\ verinhamendoncapr@hotmail.com \\ ORCID - http://orcid.org/0000-0001-8835-4927
}

\section{Eduardo José Manzini}

Professor doutor na Universidade Estadual Júlio de Mesquita Filho, Marília, São Paulo, Brasil. eduardo.manzini@unesp.br

ORCID - http://orcid.org/0000-0002-7157-8227

Recebido em 31 de março 2020

Aprovado em 11 de junho de 2020

Publicado em 8 de julho de 2020

\section{RESUMO}

O estudo teve como objetivo identificar, a partir de relatos dos professores, as concepções favoráveis e desfavoráveis em relação ao ensino, ao currículo, à avaliação e à aprendizagem do aluno com deficiência intelectual. Quatro professoras, que trabalhavam em escolas municipais no Ensino Fundamental I, em um município do interior do estado do Paraná, participaram da pesquisa. A abordagem utilizada foi a pesquisa qualitativa descritiva, por meio de entrevista semiestruturada e cadernos de conteúdo. Um roteiro foi elaborado para a entrevista e analisado por juízes. A coleta foi efetuada em duas sessões: a primeira, por meio de entrevista semiestruturada e, a segunda, utilizando o caderno de conteúdo. As concepções identificadas, por meio da análise de conteúdo, foram separadas em favoráveis e desfavoráveis em relação à aprendizagem, ao currículo, ao ensino e à avaliação de alunos com deficiência intelectual. Na concepção dos participantes: todos os alunos conseguem aprender, mas não acompanham o ritmo dos colegas da classe; o currículo adaptado é indicado para o aluno com deficiência intelectual, porém, existe uma dicotomia entre adaptar o conteúdo ou adaptar as atividades; o ensino colaborativo é o mais eficaz; a avaliação é vista como uma falha nos sistemas de ensino e ora atribuem que a avaliação deve ser igual aos demais alunos, e ora que deveria ser diferente e específica.

Palavras-chave: Educação especial; deficiência intelectual; concepção. 
http://dx.doi.org/10.5902/1984686X43241

\section{ABSTRACT}

The study aimed to identify, from the teachers' reports, the favorable and unfavorable conceptions regarding the teaching, curriculum, evaluation and learning of the student with intellectual disability. Four teachers, who worked in municipal schools in Elementary School I, in a municipality in the interior of the state of Paraná participated in the research. The approach used was qualitative descriptive research, through semi-structured interviews and content notebooks. A guide was prepared for the interview and analyzed by judges. The collection was carried out in two sessions: the first, through semi-structured interview, and the second, using the content notebook. The conceptions identified, trough content analyses, were separated into favorable and unfavorable in relation to learning, curriculum, teaching and evaluation of students with intellectual disabilities. In the participants' conception: all students are able to learn, but do not keep pace with classmates; the adapted curriculum is suitable for students with intellectual disabilities, however, there is a dichotomy between adapting content or adapting activities; the collaborative teaching is the most effective; the evaluation is seen as a failure in the education systems and sometimes they attribute that the evaluation must be equal to the other students, and now it should be different and specific.

Keywords: Special education; intellectual disability; conception.

\section{RESUMEN}

El estudio tuvo como objetivo identificar, a partir de los informes de los profesores, las concepciones favorables y desfavorables en relación con la enseñanza, el plan de estudios, la evaluación y el aprendizaje de los estudiantes con discapacidad intelectual. Cuatro profesores, que trabajaban en escuelas municipales de la Escuela Primaria I, en un municipio del interior del estado de Paraná, participaron en la investigación. El enfoque utilizado fue la investigación descriptiva cualitativa, a través de entrevistas semiestructuradas y cuadernos de contenido. Se preparó un guión para la entrevista y los jueces lo analizaron. La colección se realizó en dos sesiones: la primera, a través de una entrevista semiestructurada, y la segunda, utilizando el cuaderno de contenido. Las concepciones identificadas, a través del análisis de contenido, se separaron en favorables y desfavorables en relación con el aprendizaje, el plan de estudios, la enseñanza y la evaluación de los estudiantes con discapacidad intelectual. En la concepción de los participantes: todos los estudiantes pueden aprender, pero no mantienen el ritmo de los compañeros de clase; el plan de estudios adaptado es adecuado para estudiantes con discapacidad intelectual, sin embargo, existe una dicotomía entre adaptar el contenido o adaptar las actividades; la enseñanza colaborativa es la más efectiva; La evaluación es vista como un fracaso en los sistemas educativos y, a veces, atribuyen que la evaluación debe ser igual a la de los otros estudiantes, y ahora debe ser diferente y específica.

Palabras clave: Educación especial; discapacidad intelectual; concepción.

\section{Introdução}

A literatura na área de Educação Especial já tem pontuado a importância dos conceitos aprendizagem, currículo, ensino e avaliação do aluno com deficiência intelectual. 
http://dx.doi.org/10.5902/1984686X43241

Um desses conceitos é que o professor deve, inicialmente, conhecer a história do seu aluno para poder ensiná-lo (PADILHA, 2018). O conhecimento pode ocorrer por meio de vivência em sala de aula ou de uma avaliação mais sistematizada.

Cotidianamente, é possível identificar nos alunos o que eles sabem, quais são seus conhecimentos, quais são os interesses para mantê-los motivados para a aprendizagem, e, para isso, é necessário escuta e reconhecimento de suas falas (CARVALHO, 2011). Identificar o potencial para a aprendizagem do aluno com deficiência é algo fundamental, assim como também modificar as concepções subjacentes ao processo de ensino, aprendizagem e avaliação (ANACHE, 2012).

As concepções subjacentes somente poderão ser modificadas a partir da reflexão e preparação do professor para criar atividades pelas quais todos os alunos possam participar e aprender (STAINBACK; STAINBACK, 1999).

Se o conhecimento e avaliação do aluno é um primeiro passo, o planejamento curricular é o segundo, como têm pontuado os autores que trabalham com questões da adaptação curricular e flexibilidade curricular (BRASIL, 2003).

Ensino e aprendizagem, para alguns autores, são conceitos que caminham juntos, ou seja, quando o professor está ensinando, ele também aprende a como ensinar (BARROCO; LEONARDO; SILVA, 2012).

Com certeza, para que o ensino de alunos com deficiência intelectual ocorra, são necessárias mudanças comportamentais, pedagógicas e conceituais dos professores do ensino comum e, para tanto, as concepções desses professores precisam ser favoráveis à inclusão escolar. Portanto, pesquisar a concepção de professores sobre esse assunto é importante, pois, nem sempre os professores modificam suas práticas e podem resistir ao processo de inclusão escolar.

Assim, o presente estudo baseou-se no seguinte questionamento: a concepção do professor do Ensino Fundamental I sobre aprendizagem, currículo, ensino e avaliação do aluno com deficiência intelectual tem sido favorável ou desfavorável em relação à inclusão escolar? Portanto, tem-se como objetivo neste manuscrito: identificar, a partir de relatos dos professores do Ensino Fundamental I, as concepções favoráveis e desfavoráveis em relação à aprendizagem, ao currículo, ao ensino e à avaliação do aluno com deficiência intelectual. 
http://dx.doi.org/10.5902/1984686X43241

\section{Método}

O presente estudo é um recorte de uma pesquisa maior e configura-se em uma pesquisa qualitativa, descritiva, realizada por meio de entrevista semiestruturada e cadernos de conteúdo. Trata-se de uma amostra de conveniência e foi desenvolvida em um município do interior do Paraná, cuja rede escolar pública possuía 23 escolas. Como critério da amostra, optou-se por escolas que possuíam Salas de Recursos Multifuncionais e com maior número de alunos com deficiência intelectual frequentando o Ensino Fundamental I.

Para a seleção dos professores participantes, foram utilizados como critérios de inclusão: 1) atuar em sala de aula no ensino regular - Fundamental I; 2) trabalhar em sala de aula com aluno com deficiência intelectual. Quatro professoras atendiam a esses critérios e foram participantes do estudo, sendo que três delas trabalhavam em uma mesma escola (P2, P3, P4). O Quadro 1 indica as características das professoras.

Quadro 1 - Identificação das professoras

\begin{tabular}{|c|r|r|r|r|r|r|}
\hline Professoras & $\begin{array}{l}\text { Idade } \\
\text { (anos) }\end{array}$ & $\begin{array}{l}\text { Série que } \\
\text { lecionava }\end{array}$ & $\begin{array}{l}\text { № alunos com DI } \\
\text { Em sala de aula }\end{array}$ & $\begin{array}{l}\text { Tipo de } \\
\text { escola }\end{array}$ & $\begin{array}{l}\text { Tempo no } \\
\text { magistério }\end{array}$ & $\begin{array}{l}\text { Experiência com } \\
\text { alunos com DI }\end{array}$ \\
\hline P1 & 40 & $4^{\circ}$ ano & 01 & Municip & 20 anos & 15 anos \\
\hline P2 & 32 & $3^{\circ}$ and & 02 & Municip & 10 anos & 08 anos \\
\hline P3 & 30 & 3o and & 03 & Municip & 8 anos & 03 anos \\
\hline P4 & 32 & $2^{\circ}$ and & 02 & Municip & 15 anos & 08 anos \\
\hline
\end{tabular}

Fonte: elaboração própria (2020).

Legenda: DI - deficiência intelectual

Destas quatro professoras, apenas P2 não possuía especialização em Educação Especial, como indica o Quadro 2.

Quadro 2 - Formação das professoras

\begin{tabular}{|l|l|l|l|}
\hline Professoras & Formação & Cursos/ Especializações & \\
\hline P1 & Pedagogia & $\begin{array}{l}\text { Psicopedagogia Clinica e Institucional, Educação Especial, } \\
\text { Psicomotricidade, Gestão Escolar }\end{array}$ \\
\hline P2 & Pedagogia & Psicomotricidade & \\
\hline P3 & Pedagogia & Psicomotricidade, Educação Especial, Educação de Jovens e Adultos \\
\hline P4 & Pedagogia & Educação Especial, Psicomotricidade, Gestão Escolar \\
\hline
\end{tabular}

Fonte: elaboração própria (2020).

Dentre os procedimentos para a coleta de dados, foram utilizados a entrevista semiestruturada e o uso do Caderno de Conteúdo. 
http://dx.doi.org/10.5902/1984686X43241

Um roteiro para a entrevista foi elaborado com o propósito de buscar informações que respondessem ao objetivo da pesquisa. Esse roteiro foi analisado por dois juízes em uma reunião e após discussão, foi reformulado tendo como critério a concordância entre eles e o roteiro original (MANZINI, 2003, 2020).

As entrevistas com as quatro professoras do Ensino Fundamental I aconteceram ao final do ano letivo e foram realizadas na escola onde cada uma ministrava aulas, em uma sala de aula durante o Horário de Trabalho Pedagógico Coletivo. As quatro entrevistas aconteceram em momentos diferentes.

O Quadro 3, a seguir, refere-se à duração da coleta de dados.

Quadro 3 - Duração da coleta de dados

\begin{tabular}{|l|l|l|}
\hline Professoras & $\begin{array}{l}1^{\circ} \text { encontro } \\
\text { Entrevista }\end{array}$ & $\begin{array}{l}2^{\circ} \text { encontro } \\
\text { Caderno de conteúdo }\end{array}$ \\
\hline P1 & 41 minutos & 30 minutos \\
\hline P2 & 32 minutos & 20 minutos \\
\hline P3 & 30 minutos & 30 minutos \\
\hline P4 & 28 minutos & 25 minutos \\
\hline
\end{tabular}

Fonte: elaboração própria (2020).

As perguntas foram estabelecidas em tom de diálogo. Todas as entrevistas foram registradas em áudio por um gravador digital. Posteriormente, o áudio gravado da entrevista foi transcrito para o Caderno de Conteúdo.

O Caderno de Conteúdo é um procedimento utilizado para coletar dados de natureza verbal. Foi desenvolvido por Carolina M. Bori e colaboradores, em 1977, e empregado por vários pesquisadores brasileiros (MANZINI, 2020).

Os relatos foram transcritos no Caderno de Conteúdos em forma de colunas. As colunas foram organizadas da esquerda para a direita, de acordo com a ordem de importância para o objetivo da pesquisa, sendo a primeira coluna a mais relevante. Os nomes intitulados para cada coluna foram os mesmos em todos os cadernos. Foi organizado um Caderno de Conteúdo para cada participante, totalizando quatro cadernos.

Quadro 4 - Colunas do caderno de conteúdo

\begin{tabular}{|l|l|l|l|}
\hline $1^{\underline{a}}$ coluna & $2^{\underline{a}}$ coluna & $3^{\underline{a}}$ coluna & $4^{\underline{a}}$ coluna \\
\hline $\begin{array}{l}\text { O que é inclusão para } \\
\text { Mim }\end{array}$ & $\begin{array}{l}\text { O que ele faz } \\
\text { na sala }\end{array}$ & $\begin{array}{l}\text { Características dos alunos } \\
\text { atendidos }\end{array}$ & Outras informações \\
\hline Perguntas e respostas & Perguntas e respostas & Perguntas e respostas & Perguntas e respostas \\
\hline
\end{tabular}

Fonte: elaboração própria (2020). 
http://dx.doi.org/10.5902/1984686X43241

Para a segunda coleta, o caderno foi lido com as informações transcritas e foi perguntado aos participantes se gostariam de modificar, acrescentar ou retirar alguma fala. As falas, advindas dessa segunda coleta, foram gravadas e transcritas para análise.

A Análise do Conteúdo foi o referencial teórico utilizado. Segundo Bardin (1977), a Análise de Conteúdo é uma técnica utilizada para analisar comunicações de forma objetiva e sistemática de um conteúdo de mensagem, com indicadores quantitativos ou não, que permitem incluir conhecimentos referentes às variáveis inferidas destas mensagens. Após uma leitura previa do material completo, realizou-se uma leitura pormenorizada de cada relato, para extrair as concepções subjacentes às falas. Havendo consenso entre os juízes que analisaram as concepções, a concepção era nomeada. No exemplo a seguir, é possível identificar como as concepções foram extraídas das falas transcritas:

[...] porque quando você dá o diferente, adaptado, eles (alunos com deficiência intelectual) sabem que é diferente. Os outros (alunos) sabem também e não são todos que compreendem. Só vejo pontos negativos. Isso é exclusão!

Concepção (P1): os alunos com deficiência intelectual ficam excluídos quando as atividades são diferentes.

Após identificar todas as concepções, elas foram separadas em dois grandes temas: as concepções favoráveis e as concepções desfavoráveis em relação à inclusão escolar do aluno com deficiência intelectual no ensino regular. Em seguida, foi selecionada uma amostra das concepções favoráveis e desfavoráveis (30\% de cada) e enviadas para nova apreciação por outros dois juízes, dotados de experiência com o uso de entrevista, para aferir o nível de concordância. Em seguida, nova análise foi realizada para separar as concepções em categorias temáticas.

Para o presente estudo, optou-se por apresentar e discutir as concepções favoráveis e desfavoráveis em relação à aprendizagem, ao currículo, ao ensino e à avaliação de alunos com deficiência intelectual. Mais precisamente, as categorias favoráveis em relação: 1) à aprendizagem; 2) ao currículo e à adaptação curricular; 3) ao ensino colaborativo; e, 4) à avaliação da aprendizagem. E as categorias desfavoráveis em relação: 1) à aprendizagem; 2) ao currículo e à adaptação curricular; e, 3) à avaliação da aprendizagem. 
http://dx.doi.org/10.5902/1984686X43241

\section{Resultados e discussão}

As concepções em relação à aprendizagem, ao currículo, ao ensino e à avaliação serão apresentadas em dois grupos: primeiro as concepções favoráveis e, posteriormente, as desfavoráveis.

\section{Concepções favoráveis}

Concepções favoráveis em relação à aprendizagem

De acordo com Lefrançois (2018, p. 28), a aprendizagem "pode ser definida como mudanças relativamente permanentes no potencial para o comportamento, que resulta da experiência. Daí, que nem sempre a aprendizagem é visível no comportamento (p. 28)". Portanto, ancorado nessa definição, o professor pode avaliar o desempenho da aprendizagem do seu aluno e pode não vislumbrar que alguma mudança esteja ocorrendo. Trata-se, portanto, de avaliar o desempenho real ou potencial, conceito explorado por Vigotskii e colaboradores sobre a área de desenvolvimento potencial ou proximal (VIGOTSKII; LURIA; LEONTIEV, 1988).

As participantes P1, P2 e P3 afirmaram que é importante que o professor de sala comum conheça seus alunos, para organizarem-se, planejarem com objetivos mais definidos e obterem resultados.

(P1) [...] o professor necessita saber como é o processo de aprendizagem de alunos com DI porque senão ele também não vai ter o resultado esperado.

(P2) [...] essencial que o professor de sala de aula inclusiva, conheça seus alunos.

(P3) [...] o professor que recebe um aluno com DI teria que ter um parecer deste aluno referente ao ano anterior em sua aprendizagem.

Para melhor conhecer os interesses dos alunos, é preciso estimular a sua escuta, ouví-los, reconhecer suas falas, conhecer sua bagagem e o que os motiva, como afirmou Carvalho (2011).

Alguns participantes concebem que os alunos com DI apresentam potencialidades para a aprendizagem, como apontam os relatos:

(P2) [...] os alunos com deficiência intelectual são capazes de aprender no tempo dele.

(P2) [...] o aluno com deficiência intelectual avança na aprendizagem, mas no limite deles.

(P3) [...] os alunos com DI podem aprender os conteúdos acadêmicos .

(P3) [...] o aluno com DI avança na aprendizagem. 
http://dx.doi.org/10.5902/1984686X43241

A esse respeito, Padilha (2017) foi contundente em afirmar que o processo de ensino e aprendizagem desses alunos não pode restringir-se a qualquer conteúdo e estratégia, pois, desse modo, não Ihes possibilitará aprendizagem e nem desenvolverão suas potencialidades. Adotando uma perspectiva teórica da Psicologia Histórico-cultural, enfatizou que: "o desenvolvimento máximo de cada aluno exige conhecimento também máximo dos professores sobre o desenvolvimento das funções psíquicas superiores ou culturais e sobre a formação de conceitos cotidianos e científicos (PADILHA, 2017, p. 19)". Em Outras palavras, há necessidade de os professores capacitarem-se para poder ensinar alunos com deficiência.

Alguns relatos pontuam concepções de estratégias que podem auxiliar o ensino de alunos com DI:

(P1) [...] o aluno deve se sentar próximo ao professor, devido a sua dificuldade na aprendizagem.

(P2) [...] os alunos com maior dificuldade podem aprender melhor por meio dos colegas.

(P3) [...] o aluno com DI compreende melhor quando um colega explica a atividades a ele.

Com certeza, se o professor tem a concepção de que as práticas pedagógicas podem ser organizadas e sistematizadas, se os objetivos estão claros e se as estratégias forem selecionadas, a mediação do professor (PADILHA, 2017) ou de um aluno mais competente poderá promover a aprendizagem.

\section{Concepções favoráveis em relação ao currículo}

A aprendizagem escolar está diretamente relacionada ao currículo, que organiza os diversos níveis de ensino e as ações docentes, e que é construído a partir do projeto político pedagógico da escola, servindo como um guia: "o que, quando e como ensinar; como e quando avaliar" (BRASIL, 2003, p. 52).

Os dados coletados indicaram que todos os participantes têm a concepção definida de que a adaptação curricular é necessária para o ensino dos alunos com deficiência. Porém, nem sempre adaptação curricular tem o mesmo significado para eles.

Para alguns participantes, a adaptação deve ser nas atividades, mas o conteúdo deveria ser o mesmo: 
http://dx.doi.org/10.5902/1984686X43241

(P2) [...] o conteúdo curricular para os alunos deve ser o mesmo, porém, as atividades adaptadas.

(P2) [...] as atividades para o aluno com deficiência intelectual devem ser adaptadas por causa do ritmo e da deficiência intelectual.

(P2) [...] inclusão para o aluno com deficiência intelectual é você dar atividades adaptadas, mas dentro do conteúdo.

(P4) [...] o conteúdo a ser ensinado para alunos com DI é o mesmo, porém as atividades são adaptadas.

Essa concepção alinha-se com a perspectiva de Padilha (2018), que enfatizou que alunos com deficiência intelectual devem estudar o mesmo conteúdo que os demais alunos. Porém, também alertou que o ensino proposto para alunos com deficiência intelectual tem uma tendência a reduzir e simplificar as tarefas propostas. Essa segunda concepção também apareceu nos relatos dos participantes:

(P3) [...] o conteúdo as ser ensinado alunos com DI deve ser adaptado.

(P2) [...] o conteúdo deve ser adaptado à realidade do aluno com deficiência intelectual.

(P1) [...] as atividades escolares, os conteúdos precisam ser diferentes, adaptados ao nível da criança.

Um dos participantes citou a questão da temporalidade:

(P1) [...] O aluno com deficiência intelectual possui a adequação na temporalidade.

Nesta direção, a literatura oficial pontua que é possível modificar o tempo para que alguns conteúdos e objetivos sejam apropriados pelo aluno com necessidades educacionais especiais (BRASIL, 1999). Um exemplo seria o prolongamento de um ano ou mais de permanência do aluno na mesma série ou no ciclo.

Um participante avaliou a não dificuldade em realizar adaptações

(P2) [...] fazer a adaptação curricular para o aluno com deficiência intelectual não é difícil.

Interessante notar que P2 tem uma concepção de que a adaptação curricular deve incidir sobre o conteúdo, então, é possível questionar: realmente é fácil realizar essa adequação? Não estaria P2 fundamentando-se na tendência de reduzir o conteúdo ao invés de adaptar as atividades para manter o conteúdo?

A literatura da área tem pontuado que a adaptação curricular envolve o planejamento da turma, como um todo, deve respeitar o ritmo e as especificidades de cada aluno. Ao planejar o conteúdo e pensar nas atividades relacionadas a esse conteúdo, o professor deve realizar um questionamento, analisando, a priori, o objetivo principal, de como fazer para que todos participem, inclusive o aluno com deficiência 
http://dx.doi.org/10.5902/1984686X43241

intelectual, que atitudes, habilidades e conteúdos deve priorizar e quais expectativas deve ter em relação ao aluno com deficiência intelectual (STAINBACK; STAINBACK, 1999).

Para que essas adaptações curriculares ocorram de forma correta, é preciso que se inicie no projeto político pedagógico da escola, no currículo ou plano de ensino do professor e na programação individual de ensino do aluno, elaborada pelo professor (BRASIL, 1999), tarefas nem sempre fáceis de serem praticadas no cotidiano escolar.

\section{Concepções favoráveis em relação ao ensino colaborativo}

Ensino colaborativo ou ensino cooperativo são utilizados na literatura estrangeira, que denomina a parceria entre professores da educação especial e professores do ensino comum (FELIPPE; CAPELLINI, 2014).

No Brasil, Capellini (2001) destacou a importância da colaboração e cooperação desses profissionais da Educação Especial e do ensino comum, em prol de um ensino inclusivo, a partir do qual se pudessem respeitar os direitos desse aluno com deficiência, e também ao seu aproveitamento escolar e desempenho na aprendizagem. Nesse sentido, a colaboração é um fator determinante para o ensino colaborativo.

A colaboração está relacionada à contribuição, ou seja, o indivíduo deve interagir com o outro, existindo ajuda mútua ou unilateral (CAPELLINI, 2008).

Os relatos a seguir tratam sobre o trabalho colaborativo:

(P1) [...] a aprendizagem do aluno com deficiência intelectual é baseada no trabalho colaborativo.

(P1) [...] o trabalho colaborativo entre professor regular e professor da Sala de Recursos Multifuncionais são indispensáveis para os conteúdos serem ensinados.

(P2) [...] o trabalho em sala de aula deve ser colaborativo entre os alunos.

(P3) [...] o trabalho colaborativo entre o professor sala regular e de Sala de Recursos Multifuncionais é fundamental. (P3).

A colaboração está relacionada à contribuição, ou seja, o indivíduo deve interagir com o outro, existindo ajuda mútua ou unilateral (CAPELLINI, 2008).

Entre as formas de trabalho em conjunto, o ensino colaborativo tem sido utilizado para favorecer a inclusão escolar, envolvendo a parceria direta entre professores da Educação Comum e Especial. O Ensino Colaborativo pode se efetivar de várias maneiras: um professor como suporte, o professor da Educação Comum e o educador especial atuam juntos em sala de aula, mas um apresenta as instruções, enquanto o outro providencia o apoio aos estudantes. Pode ser realizado o rodízio, trocando os papéis (CAPELLINI, 2008). 
O trabalho colaborativo desenvolvido pelo professor especialista junto aos professores do ensino comum tem contribuído para a autonomia e aprendizagem dos alunos e, também, para a formação dos professores (CAPELLINI, 2004).

O objetivo do trabalho colaborativo é criar opções para aprender e prover apoio aos alunos em sala de aula do ensino regular, combinando as habilidades do professor comum e do professor especialista (MENDES, 2006). Segundo a autora, isso envolve um compromisso dos professores, dos gestores, do sistema escolar e até da comunidade.

É fato que ainda é possível encontrar, por parte das escolas, grande dificuldade em realizar esse trabalho colaborativo. Dificuldades essas que estão relacionadas à formação dos professores, a disponibilidade de horário para esses professores por parte da gestão escolar, na aceitação e importância desse processo na escola (CARVALHO, 2018; DIAS, 2018).

\section{Concepções favoráveis em relação à avaliação da aprendizagem}

Avaliar a aprendizagem no contexto da escola sempre foi um grande desafio, pois tem relação com a prática pedagógica em sala de aula.

Nos relatos dos participantes, é possível aferir que a escola parece determinar algumas concepções sobre a avaliação:

(P2) [...] no conselho de classe deve ser registrada a nota da avaliação normal e da avaliação específica.

(P1) [...] a avaliação da aprendizagem do aluno com deficiência intelectual deve ser de acordo com o conteúdo que ele está aprendendo e não da série em que cursa. $\mathrm{Na}$ avaliação, é preciso verificar quanto o aluno $\mathrm{DI}$ avançou em relação a ele mesmo, para que não haja erros que possam atrapalhar seu desenvolvimento.

(P2) [...] a avaliação para o aluno com deficiência intelectual deve seguir o sistema educacional do município.

A determinação do sistema de avaliação é uma das reponsabilidades administrativas da escola, que deve ser efetivado com seriedade, com critérios claros e bem fundamentados (BRASIL, 2000).

Anache (2012) destacou que é importante que se construa uma avaliação que potencialize o processo de aprendizagem do aluno com deficiência intelectual e, para isso, é necessário que ocorram mudanças na concepção de ensino, aprendizagem e, é claro, na avaliação.

Sobre o tipo de avaliação a ser aplicada ao aluno com DI, os participantes relataram:

(P1) [...] a avaliação de aprendizagem do aluno com DI deve ser diferente. 
http://dx.doi.org/10.5902/1984686X43241

(P2) [...] o aluno com deficiência intelectual deve ter avaliação específica para ele.

A literatura oficial salienta que é importante que a avaliação da aprendizagem para os alunos com deficiência deve envolver os aspectos relacionados ao seu desenvolvimento (biológico, intelectual, motor, emocional social e comunicação); o nível de competência curricular (competência do aluno em relação aos conteúdos curriculares anteriores e os que serão desenvolvidos) e o estilo de aprendizagem (BRASIL, 1999).

Alguns participantes ressaltaram a concepção de avaliação contínua, como indicam os relatos que seguem:

(P4) [...] avaliação para alunos com DI deveria ser diária e continua para analisar o processo de desenvolvimento no nível deles.

(P3) [...] é importante realizar avaliação diagnóstica destes alunos no início do ano.

(P3) [...] a avaliação do rendimento escolar deve ser continua.

De acordo com o Conselho Nacional de Educação (BRASIL, 2001), a avaliação deve ter como foco o desenvolvimento e a aprendizagem do estudante, ser um processo permanente que possa analisar e interferir na aprendizagem, identificar as potencialidades, mas, também, as necessidades educacionais dos alunos e como a escola pode agir diante dessas necessidades.

\section{Concepções desfavoráveis}

Concepções desfavoráveis em relação à aprendizagem

Alguns participantes relataram aspectos relacionados ao ritmo do aluno com deficiência intelectual:

(P1) [...] O aluno com deficiência intelectual é lento, possui um ritmo lento na aprendizagem.

(P1) [...] O aluno avança, mas não o suficiente para acompanhar a série.

(P2) [...] O aluno com DI não consegue finalizar as atividades em tempo real como os demais, mesmo as atividades sendo adaptadas.

Nos relatos destacados prevalecem respostas que consideram o aluno com DI muito lento, como aquele aluno que "aprende nesse ritmo". Assim, esse poderia ser o motivo pelo qual o aluno possui um déficit na aprendizagem: (P4) "o aluno com DI tem dificuldade de aprendizagem".

Leonel e Leonardo (2014) encontram as mesmas concepções quando entrevistaram professores que trabalhavam no Ensino Fundamental na modalidade de Educação 
Especial. Para os autores, essas concepções reforçam a ideia de que o desenvolvimento do aluno com deficiência intelectual é abaixo da expectativa tanto dos professores como das escolas. Fundamentados na Teoria Histórico-Cultural, os autores discutem os embasamentos teóricos, pois, o desenvolvimento somente é impulsionado se a aprendizagem ocorrer.

Além de uma aprendizagem lenta, os participantes relataram que seus alunos necessitam de um tempo maior para aprender os conteúdos, o que os diferencia dos demais alunos da sala: (P4) "o aluno com DI dever ter a oportunidade de terminar a atividade em sala de aula em outro momento ou dia seguinte quando não conseguir no mesmo dia".

A concepção de que cada aluno tem seu próprio tempo para aprender e que isso exige dos professores uma programação individualizada também foi corroborada no estudo de Leonel e Leonardo (2014, p.549): "identificamos que a maioria das participantes, ao serem questionadas, relataram que os alunos, respeitando seu tempo de aprendizagem, estão aprendendo".

Nesse sentido, é importante que os docentes compreendam a verdadeira função pedagógica no cotidiano escolar, pois eles destacam ser esse o grande desafio em sala de aula. Eles sentem-se responsáveis pelo avanço na aprendizagem do aluno, mas ignoram que o avanço não depende somente de sua prática:

(P2) [...] o aluno com DI não consegue finalizar as atividades em tempo real como os demais, mesmo as atividades adaptadas.

(P1) [.. mesmo sendo adaptadas as atividades, o currículo flexível e adaptado, ao aluno com deficiência intelectual não consegue acompanhar os demais alunos da série, ou ainda, os conteúdos necessários.

(P3) [...] o aluno dificilmente termina as atividades ao mesmo tempo em que os demais alunos.

Para Marchesi (2004), uma das melhores atitudes no trabalho do professor em sala de aula é iniciar pela ideia de como seu aluno aprende, e questionar qual seria forma mais hábil e a melhor maneira de ensiná-lo. Para isso, é necessário que se estabeleça uma boa relação entre professor, aluno e o conteúdo. Isso explica, segundo o autor, como o aluno aprende os conteúdos, pela ação do professor de forma instrutiva. Para esse autor, é preciso considerar três fatores para sua aprendizagem efetiva: 1) conhecimentos prévios; 2) a atividade mental construtiva; 3) a motivação para aprender.

Um dos participantes destacou a motivação e sua relação com a aprendizagem: (P4) "[...] para o aluno com DI a dificuldade em aprender é maior que a vontade de aprender". 
http://dx.doi.org/10.5902/1984686X43241

A atribuição de juízo de valor de P4 superestima a dificuldade e diminuiu a motivação, a concepção subjacente a essa verbalização é que mesmo o estudante tendo vontade de aprender, ele não supera as dificuldades inerentes a sua condição de deficiência intelectual.

Uma das recomendações de documento oficial para a construção de escolas inclusivas, no que se refere à formação de professores, é o exercício da autonomia para que estes professores possam utilizar suas habilidades na adaptação do currículo e das instruções (BRASIL, 2006).

Buscou-se saber se os alunos estavam aprendendo ou não, se conseguiam acompanhar a série e respectivos conteúdos. Todos os participantes relataram que os alunos, mesmo respeitando seu tempo, com atividades adaptativas, um currículo flexível, não avançavam de forma a acompanhar a série em que se encontravam, como se pode verificar a seguir:

(P1) [...] os alunos com DI dificilmente acompanham a série em que estão matriculados.

(P2) [...] o aluno com deficiência intelectual mesmo avançando na aprendizagem, ainda não alcança o nível da série.

(P4) [...] o aluno com DI dificilmente avança na aprendizagem, não consegue.

(P3) [...] os alunos com DI não acompanham o conteúdo.

(P4) [...] os alunos com DI tem dificuldade de aprendizagem.

A esse respeito, Leonel e Leonardo (2014) ressaltam que, independente ou não do comprometimento intelectual da criança, o professor precisa ter um olhar diferenciado para o processo de desenvolvimento e aprendizagem infantil. Esse olhar, segundo os autores, precisa ir além das carências e limitações, com base em suas habilidades e no aumento de seu potencial.

Para Padilha (2018), na maioria dos casos, a maior dificuldade da pessoa com deficiência intelectual é:

o desenvolvimento da atividade consciente e volitiva, ou seja, a apropriação subjetiva, intencional, da realidade objetiva que está fora do interior de cada um. Tornar próprio o que é da realidade, ir além das aparências ultrapassando e superando as limitações biológicas por meio do processo educativo. (PADILHA, 2018, p. 172).

\section{Concepções desfavoráveis em relação ao currículo}

No relato a seguir, uma participante apresenta a questão da adaptação curricular: 
http://dx.doi.org/10.5902/1984686X43241

(P1) [...] mesmo sendo adaptadas as atividades, o currículo flexível e adaptado, o aluno com deficiência intelectual não consegue acompanhar os demais alunos da série, ou ainda, os conteúdos necessários.

A adaptação curricular é uma forma para transformar o mesmo conteúdo do currículo em um meio acessível ao aluno com deficiência.

Concepções contrárias a essa estão presentes em ambientes escolares que têm a participação de professores do ensino comum e especializados.

O estudo de Muniz e Galvani (2020) apontou que os professores participantes da pesquisa, que ensinavam em escolas com a presença de professores da classe comum e do ensino especial, acreditavam que, por meio da adaptação curricular, os alunos com deficiência acompanhariam os colegas da classe, com o mesmo conteúdo escolar. Para os autores, o ensino colaborativo e a adaptação curricular são estratégias decisivas para a participação de alunos com deficiência intelectual.

Um dos participantes mencionou que:

(P3) [...] o aluno com DI não gosta de realizar atividades diferentes dos demais alunos.

Há que se questionar o porquê de ele não gostar: como são as atividades propostas? A afirmação de P3 demonstra que a experiência vivenciada por ela, ao realizar atividades diferentes para o seu aluno com deficiência intelectual, não foi positiva, daí a interiorização de uma concepção desfavorável à adaptação curricular. Com certeza, as atividades motivadoras atraem alunos com e sem deficiência. O gostar e não gostar da atividade diferenciada não é intrínseco ao aluno com deficiência intelectual, e nem ao aluno sem deficiência, mas é algo que se estabelece nas relações concretas propostas para o ensino de conteúdos.

\section{Concepções desfavoráveis em relação à avaliação da aprendizagem}

O início do processo educacional dos alunos com deficiência exige a necessidade de avaliação, que irá nortear a tomada de decisões pedagógicas que são essenciais para as adequações curriculares (BRASIL, 2003). São os sistemas escolares que deverão constituir os processos de avaliação no interior da escola.

Esses processos de avaliação constituídos pelos sistemas educacionais são vivenciados pelos professores que avaliam como eles funcionam na prática e, a partir dessa experiência, criam avaliações ou concepções sobre eles. Nos relatos que seguem, é possível verificar isso: 
http://dx.doi.org/10.5902/1984686X43241

(P1) [...] existem lacunas no processo de avaliação da aprendizagem do aluno com DI.

(P2) [...] para o sistema educacional, a avaliação do aluno com deficiência intelectual deve ser igual.

Nota-se, nos relatos, que a mensagem demonstra que existem falhas no processo de avaliação da aprendizagem que são constituídos pelos sistemas de ensino, e que, para alguns, a avaliação não deve ser diferenciada. A diferenciação ou não da avaliação do aluno com deficiência intelectual parece ser o cerne do problema nas concepções dos participantes:

(P3) [...] a avaliação dos alunos com DI tem que ser a mesma que os demais alunos.

(P4) [...] alunos com DI deveriam ter avaliações diferentes dos demais alunos.

Um dos documentos oficiais sobre esse tema aponta que a avaliação para este público-alvo deve ser relacionada ao aluno, ao contexto educacional e familiar.

Quanto ao aluno, a avaliação deve focalizar:

- os aspectos do desenvolvimento (biológico, intelectual, motor, emocional, social, comunicação e linguagem);

- o nível de competência curricular (capacidade do aluno em relação aos conteúdos curriculares anteriores e a serem desenvolvidos;

- o estilo de aprendizagem (motivação, atenção, interesses acadêmicos, estratégias próprias de aprendizagem, tipos preferenciais de agrupamentos que facilitam a aprendizagem e condições físico-ambientais mais favoráveis para aprender. (BRASIL, 2003, p. 54).

Apesar das diretrizes apresentadas, a tomada de decisão, para reter ou promover o aluno com deficiência intelectual para outra série, compete ao grupo de responsáveis pela elaboração das adequações curriculares do aluno (BRASIL, 2003).

Apesar da tentativa de nortear as questões relativas a este tema, é possível encontrar concepções que denotam a incapacidade do aluno com deficiência intelectual, como expressa no relato a seguir (P4): "[...] aluno DI será sempre fraco na avaliação tradicional".

Um dos participantes citou a questão do professor leitor, que é um serviço de apoio na rede de ensino pesquisada para auxiliar nas avaliações externas: (P1) "[...] o professor leitor não resolve a questão da avaliação do aluno com DI".

Neste contexto, o participante estava se referindo as avaliações externas de larga escala, relacionadas às avaliações de controle do Ministério da Educação, como a 
Provinha Brasil, ANA (Avaliação Nacional da Alfabetização) a Prova Brasil (BRASIL, 2007).

Sobre esse tema, no estudo desenvolvido por Silva e Meletti (2014), as conclusões dos autores foram que existia um baixo número de matrículas da população da Educação Especial para as provas de larga escala, que havia uma defasagem em relação a idadesérie, e que os alunos com deficiência intelectual alcançaram baixo desempenho nas provas.

Finalizado este tema, a dificuldade da avaliação da aprendizagem esteve presente no relato de todos os participantes do estudo, o que denota necessidade de formação dos professores em relação a ele.

\section{Considerações finais}

O estudo possibilitou estudar as concepções subjacentes aos conceitos de aprendizagem, currículo, ensino e avaliação do aluno com deficiência intelectual.

As concepções em relação à aprendizagem do aluno com deficiência intelectual indicaram, por um lado, que os alunos são capazes de aprender e que têm o seu ritmo próprio, por outro, a aprendizagem não é suficiente para acompanhar o grupo, a série e a sala de aula. Alguns participantes inclusive indicaram estratégias mais eficazes para o ensino e para a aprendizagem: explicação do conteúdo por outros alunos, atenção individual para o aluno com deficiência intelectual e a proximidade física do professor.

Em relação ao currículo, todos os participantes indicaram a necessidade de uma adequação curricular, porém, teceram comentários sobre a dificuldade de aprendizagem mesmo com as adaptações curriculares. Há uma clara dicotomia nas concepções dos participantes em relação a esse tema: para alguns, o conteúdo deve ser diferente, para outros, o conteúdo deve igual e as atividades diferentes.

Sobre o conceito de ensino, a maioria das participantes reconhece o trabalho colaborativo como um recurso fundamental no processo de inclusão dos alunos, ao mesmo tempo em que auxilia os professores no trabalho em conjunto. Reconhecem a dificuldade da realização dessa tarefa.

Há que se considerar que a avaliação tem sido um grande problema, segundo relato das participantes, pois se fala em inclusão e o aluno precisa fazer uma avaliação no nível dele de adaptação curricular e outra no nível da turma, a qual ele não consegue realizar. 
As concepções dos professores em relação à avaliação parecem terem sido constituídas a partir das vivências dos sistemas educacionais das participantes. Para elas, existem falhas nos sistemas educacionais: ora atribuem que a avaliação deve ser igual aos demais alunos do sistema, e que deveriam ser diferentes.

A avaliação com foco na aprovação do aluno é um ponto negativo, pois há dúvidas entre as participantes da pesquisa, quanto à questão de aprovar ou reprovar o aluno com $\mathrm{DI}$ e quais procedimentos seriam corretos.

\section{Referências}

ANACHE, Alexandra Ayach. Dimensões subjetivas envolvidas na avaliação da aprendizagem de pessoas com deficiência intelectual. In: MARTINEZ, Mitjáns Albertina; SCÓZ, Beatriz Judith Lima; CASTANHO, Marisa Irene Siqueira. Ensino e aprendizagem: a subjetividade em foco. Brasília, DF: Líber Livro. 2012. p. 219-247.

BARDIN, Laurence. Análise do conteúdo. Lisboa/ Portugal: Edições 70, 1977.

BARROCO, Sonia Mari Shima; LEONARDO, Nilza Sanches Tessaro; SILVA, Tânia dos Santos Alvarez da. Educação especial e teoria histórico cultural: em defesa da humanização. Maringá: EDUEM, 2012.

BRASIL. Adaptações curriculares em ação: estratégias para a educação de alunos com necessidades educacionais. Secretaria de Educação Especial. Brasília, DF: MEC/ SEEP, 1999.

BRASIL. Projeto Escola Viva - Garantindo o acesso e permanência de todos os alunos na escola - Alunos com necessidades educacionais especiais. Adaptações curriculares de grande porte. Brasília, DF: Ministério da Educação, Secretaria de Educação Especial, 2000.

BRASIL. Resolução no 2, de 11 de setembro de 2001. Institui Diretrizes Nacionais para a Educação Especial na Educação Básica. Brasília, DF, 2001. Disponível em: http://portal.mec.gov.br/cne/arquivos/pdf/CEB0201.pdf. Acesso em: 10 dez. 2018.

BRASIL. Estratégias para a educação de alunos com necessidades educacionais especiais. Brasília, DF: Ministério da Educação, Secretaria de Educação Especial, 2003. (Saberes e práticas da inclusão; 4).

BRASIL. Ministério da Educação. Saberes e práticas de inclusão: recomendações para a construção de escolas inclusivas. Brasília, DF: MEC, Secretaria da Educação Especial, 2006.

BRASIL. Ministério da Educação. Portaria Normativa no- 10, de 24 de abril de 2007. Brasília, DF, 2007. Disponível em: http://download.inep.gov.br/educacao_basica/provinha_brasil/legislacao/2007/provinha_br 
http://dx.doi.org/10.5902/1984686X43241

asil_portaria_normativa_n10_24_abril_2007.pdf. Acesso em: 25 maio 2020.

CAPELLINI, Vera Lúcia Messias Fialho. A inclusão de alunos com necessidades educacionais especiais em classes comuns: avaliação do rendimento acadêmico. 2001. Dissertação (Mestrado em Educação Especial) - Centro de Educação e Ciências Humanas, Universidade Federal de São Carlos, São Carlos, 2001.

CAPELLINI, Vera Lúcia Messias Fialho. Avaliação das possibilidades de ensino colaborativo no processo de inclusão escolar do aluno com deficiência mental. 2004. Tese (Doutorado em Educação Especial) - Universidade Federal de São Carlos, São Carlos, 2004.

CAPELLINI, Vera Lúcia Messias Fialho. Práticas em educação especial e inclusiva na área da deficiência mental. Bauru: MEC/FC/SEE, 2008.

CARVALHO, Rosita Edler. Removendo barreiras para a aprendizagem: educação inclusiva. Porto Alegre: Mediação, 2011.

CARVALHO, Tereza Cristina de. Desafios e possibilidades de um trabalho colaborativo para a formação continuada com docentes do ensino médio público. 2018. Tese (Doutorado em Educação) - Faculdade de Filosofia e Ciências, UNESP, Marília, 2018.

DIAS, Sabrina Alves. Atuação colaborativa entre o professor do atendimento educacional especializado e do ensino regular: a importância da gestão. 2018. Tese (Doutorado em Educação) - Faculdade de Filosofia e Ciências, UNESP, Marília, 2018.

FELIPPE, Neide Maria de Andrade; CAPELLINI, Vera Lúcia Messias Fialho. O processo colaborativo entre educação especial e educação comum na inclusão escolar do aluno autista. In: RODRIGUES, Olga Maria Piazentin Rolim; CAPELLINI, Vera Lúcia Messias Fialho. (org.). Práticas inclusivas: fazendo a diferença. Rio de Janeiro: Wak Editora, 2014.

LEFRANÇOIS, Guy R. Teorias da aprendizagem: o que o professor disse. São Paulo: Cengage Learning, 2018.

LEONEL, Waléria Henrique dos Santos; LEONARDO, Nilza Sanches Tessaro. Concepções de professores da educação especial (APAEs) sobre a aprendizagem e desenvolvimento do aluno com deficiência intelectual: um estudo a partir da teoria Vygotskiana. Rev. Bras. Ed. Esp. Marília, v.20, n.4, p.541-554, 2014.

MANZINI, Eduardo José. Análise de entrevista. Marília: Abpee, 2020.

MANZINI, Eduardo José. Considerações sobre a elaboração de roteiro para entrevista semiestruturada. In: MARQUEZINE, Maria Cristina.; ALMEIDA, Maria Amélia.; OMOTE; Sadao (org.). Colóquios sobre pesquisa em educação especial. Londrina: Eduel, 2003. p.11-25.

MARCHESI, Álvaro. A prática das escolas inclusivas. In: COLL, César; MARCHESI, 
Álvaro; PALACIOS, Jesús (org.). Transtornos do desenvolvimento e necessidades educativas especiais. Tradução de Fátima Murad. 2. ed. Porto Alegre: Artmed, 2004. p.31-48.

MENDES, Enicéia Gonçalves. Colaboração entre ensino regular e especial: o caminho do desenvolvimento pessoal para a inclusão escolar. In: MANZINI, Eduardo José. (org.). Inclusão e acessibilidade. Marília: Abpee, 2006. p. 29 - 41.

MUNIZ, Joice Daiane; GALVANI, Marcia Duarte. Ensino colaborativo e adaptação curricular: atuação e concepção dos professores no processo de inclusão escolar. In: MENDES, Enicéia Gonçalves et al. (org.). Da teoria à práxis: vivenciando a colaboração no dia a dia escolar, Marília: Abpee, 2020. p. 15-26.

PADILHA, Anna Maria Lunardi. Desenvolvimento psíquico e educação escolar dos estudantes com deficiência intelectual. In: ALMEIDA; Maria Amélia; MENDES, Enicéia Gonçalves; POSTALLI, Lidia Maria Marson. (org.). Práticas pedagógicas inclusivas em contextos escolares. Marília: Abpee, 2018. p.161-180

PADILHA, Anna Maria Lunardi. Desenvolvimento psíquico e elaboração conceitual por alunos com deficiência intelectual na educação escolar. Rev. Bras. Ed. Esp., Marília, v.23, n. 1, p. 9-20, 2017.

SILVA, Mariana Cesar Verçosa; MELETTI, Silvia Márcia Ferreira. Estudantes com necessidades educacionais especiais nas avaliações em larga escala: Prova Brasil e ENEM. Rev. Bras. Ed. Esp., Marília, v. 20, n. 1, p. 53-68, 2014.

STAINBACK, Susan; STAINBACK, William. Inclusão: um guia para educadores. Porto Alegre: Artes Médicas Sul, 1999. p. 230-332.

VIGOTSKII, Lev Semenovich; LURIA, Alexander Ramanovich; LEONTIEV, Alex N. Linguagem, desenvolvimento e aprendizagem. São Paulo: ícnone; São Paulo: Editora da Universidade de São Paulo, 1988. p.103-118.

\section{Correspondência}

Vera Lucia Mendonça Nunes - Universidade Estadual Júlio de Mesquita Filho, Campus Marília, Av. Higino Muzi Filho, 737, Portaria A, Mirante, Marília, São Paulo - Brasil.

CEP: $17525-900$

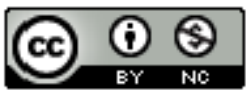

This work is licensed under a Creative Commons Attribution-NonCommercial 4.0 International (CC BY-NC 4.0) 